\title{
Avaliação do Concreto Leve Estrutural com EPS Reciclado
}

Evaluation on Structural Lightweight Concrete with EPS Recycled

Evaluación de Hormigón Ligero Estructural con EPS Reciclado

\author{
Beatriz Correa Xavier \\ Engenheira Civil, CEULP-ULBRA, Brasil. \\ beatrizeng14@gmail.com \\ Fabrício Bassani \\ Professor Mestre, CEULP-ULBRA, Brasil. \\ fabriciobassani@ceulp.edu.br \\ André Soares Mendes \\ andre.ifto@gmail.com
} Graduando em Engenharia Civil, CEULP-ULBRA, Brasil. 


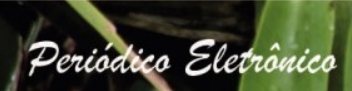

\section{INTRODUÇÃO}

Devido às crescentes solicitações estruturais e econômicas, as edificações modernas requerem o uso racional do concreto. O concreto leve estrutural (CLE) se mostra um material eficiente para a redução do peso próprio da estrutura e, como consequência, tornam-se possíveis diversos usos que, segundo CATOIA (2012), se destacam por razões de viabilidade técnica e econômica. Este tipo de concreto especial é aplicado em estruturas onde grande parte das solicitações das estruturas é consequência do peso próprio, como pontes, edificações de múltiplos andares, plataformas marítimas flutuantes e até na economia no uso de concreto na fundação, além de tornar mais fácil o transporte e montagem de peças pré-moldadas de concreto.

As exigências atuais do mercado da construção civil tendo obras com desenhos cada vez mais ousados e/ou tamanhos maiores, aliado ao controle de custos cada vez mais restritivos faz com que a Engenharia Civil busque evoluções tecnológicas para atendimento destas necessidades. Esta busca tem levado a construção civil a otimizar os processos e reduzir os custos. Um desses casos é a utilização de materiais alternativos, para executar concreto estrutural leve.

O concreto estrutural tradicional responde por uma grande parcela do peso próprio de qualquer estrutura, o que impacta diretamente no custo da fundação. Como diz ROSSIGNOLO e OLIVEIRA (2007):

A redução da massa específica do concreto, com a manutenção da resistência mecânica, propicia a redução do peso próprio da estrutura e, consequentemente, das cargas na fundação, reduzindo, assim, o custo final da obra, especialmente com a utilização da tecnologia da pré-fabricação.

Outro aspecto importante do atual estágio da engenharia civil é a utilização de materiais recicláveis oriundos ou não do Resíduo de Construção e Demolição (RCD), isto é bastante interessante porque a construção civil é uma das indústrias que mais utilizam materiais naturais em sua atividade.

\subsection{OBJETIVOS}

\subsubsection{Objetivo Geral}

Avaliar as propriedades físicas do concreto leve estrutural com EPS reciclado, através de ensaios laboratoriais. 


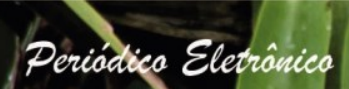

\subsubsection{Objetivos Específicos}

- Definir dosagens utilizando EPS reciclado;

- Determinar a Resistência a Compressão Axial;

- Avaliar a Absorção de Água, e Massa Específica;

- Verificar a Resistência à Tração por Compressão Diametral.

\section{METODOLOGIA}

O presente trabalho tem como objetivo produzir um material que possa ser classificado como CLE a partir de um traço referência ( $T-0)$ de Concreto de Alto Desempenho (CAD) descrito por ACI SP-154, 1995 apud MEHTA e MONTEIRO, conforme a tabela 1.

Tabela 1: Dosagem do traço referência de CAD

\begin{tabular}{ccc}
\hline Materiais & Relação em massa & Quantidade $\left(\mathbf{k g} / \mathbf{m}^{\mathbf{3}}\right)$ \\
\hline Cimento & 1 & 416 \\
Sílica & 0,08 & 34 \\
Agregado Miúdo & 1,77 & 737 \\
Agregado Graúdo & 2,47 & 1030 \\
Água & 0,36 & 153 \\
Aditivo & 0,0072 & 3 \\
\hline
\end{tabular}

Fonte: MEHTA; MONTEIRO; apud ACI SP-154, 1995.

As características físicas obtidas do traço de CAD descrito por ACI SP-154, estão descritas na tabela 2.

Tabela 2: Características físicas do traço de CAD

\begin{tabular}{ccc}
\hline Idade & Resistência à Compressão Axial (MPa) & Abatimento do Tronco de Cone (cm) \\
\hline 1 & 35 & 20 \\
3 & 52 & \\
28 & 82 & \\
\hline
\end{tabular}

Fonte: METHA; MONTEIRO; apud ACI SP-154, 1995.

A fim de se determinar a dosagem ótima de pérolas de EPS, primeiramente foi determinado um traço referência, sem adição de EPS, a partir do qual foram adicionadas diferentes quantidades de pérolas de EPS gradativamente, conforme SILVA et al. (2014), a fim de diminuir a massa específica do concreto, conforme tabela 3. 
Tabela 3: Dosagem de EPS em função do volume de cimento Portland

\begin{tabular}{ccccc}
\hline Traço & $\begin{array}{c}\text { Massa de pérolas } \\
\text { de EPS }(\mathbf{g})\end{array}$ & $\begin{array}{c}\text { Volume de pérolas } \\
\text { de EPS }\left(\mathbf{m}^{\mathbf{3}}\right)\end{array}$ & $\begin{array}{c}\text { Volume proporcional } \\
\text { ao cimento }\end{array}$ & $\begin{array}{c}\text { Porcentagem de EPS em } \\
\text { função do volume de cimento }\end{array}$ \\
\hline T-0 & 0 & 0 & 0 & 0 \\
T-1 & 100 & 0,009 & 1,43 & $143 \%$ \\
T-2 & 200 & 0,02 & 2,86 & $286 \%$ \\
T-3 & 400 & 0,04 & 5,73 & $576 \%$ \\
\hline
\end{tabular}

Fonte: AUTOR, 2015.

Foi feito ensaio de abatimento de tronco de cone, depois foram moldados corpos de prova cilíndricos com dimensões $100 \times 200 \mathrm{~mm}$ para os ensaios de compressão axial e corpos de prova com dimensões $150 \times 300 \mathrm{~mm}$ para ensaios de tração por compressão diametral.

Para cada cada idade foram ensaiados 2 corpos de prova à resistência à compressão, 2 corpos de prova para resistência à tração por compressão diametral e 3 corpos de prova para absorção de água.

Os ensaios de resistência a compressão e de tração por compressão diametral foram realizados no laboratório de materiais e estruturas do Ceulp/Ulbra, na prensa PC 200 L EMIC com capacidade de resistência de 200 toneladas.

\subsection{MATERIAIS UTILIZADOS E SUAS PROPRIEDADES}

Para o desenvolvimento do trabalho foram adotados materiais encontrados na região de Palmas/TO.

\subsubsection{Cimento}

Foi utilizado o cimento Portland tipo CPV ARI (Alta Resistência Inicial), fabricado pela Cimentos Planalto - CIPLAN.

\subsubsection{Areia}

Foi adotada areia da região de Palmas doada pela Castelo Forte Materiais para Construção extraída pela Mineração Capital. A areia utilizada apresentou massa específica de $2660 \mathrm{~kg} / \mathrm{m}^{3}$, massa unitária de $1,42 \mathrm{~kg} / \mathrm{m}^{3}$, dimensão máxima característica de $4,8 \mathrm{~mm}$ e foi classificada como areia média.

\subsubsection{Brita}

A brita utilizada foi doada pela Castelo Forte Materiais para Construção localizado em PalmasTO. A brita adotada apresentou massa específica de $2710 \mathrm{~kg} / \mathrm{m}^{3}$, massa unitária de $1,35 \mathrm{~kg} / \mathrm{m}^{3}$, dimensão máxima característica de $19,0 \mathrm{~mm}$, é uma brita granítica e foi classificada como areia média. 


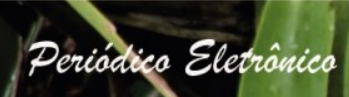

\subsubsection{Sílica Ativa}

A sílica ativa utilizada foi fornecida pela empresa Silmix, é um produto resultante do processo de fabricação do sílicio metálico ou do ferro-silício, que gera o gás SiO, que ao sair do forno oxida-se formando o dióxido de silício (SiO2). A sílica possui massa específica de $2220 \mathrm{~kg} / \mathrm{m}^{3}$, formato de partícula esférica, diâmetro médio de 0,2 $\mu \mathrm{m}$, teor mínimo de $\mathrm{SiO} 2$ de $85 \%$ e umidade máxima de $3 \%$.

\subsubsection{Aditivo Superplastificante}

Foi utilizado o aditivo superplastificante Sika ViscoCrete ${ }^{\circledR} 3535$ CB. De acordo com a ficha técnica do produto, é classificado como um aditivo superplastificante de pega normal, de terceira geração, composto basicamente por uma solução de policarboxilato em meio aquoso. É um líquido viscoso de cor castanho, com massa específica entre $1060 \mathrm{~kg} / \mathrm{m}^{3}$ à $1100 \mathrm{~kg} / \mathrm{m}^{3}$, e $\mathrm{pH}$ de 4 à 6.

\subsubsection{EPS}

O EPS utilizado foi recolhido dos despejos da obra do Ibis Hotel da construtora Inovatec em Palmas-TO, em que o fornecedor é a Isoeste Indústria e Comércio de Isolantes Térmicos Ltda. De acordo com o laudo técnico do produto fornecido pela Isoeste, é classificado como tipo $\mathrm{F}$ segundo especificação BF216 da BASF (Badische Anilin und Soda-Fabrik), que é uma empresa química alemã. Esta especificação contempla a presença de retardante a chama na composição da matéria prima fornecida pela BASF. A massa específica do EPS é $11 \mathrm{~kg} / \mathrm{m}^{3}$ e sua condutividade térmica é de $0,025 \mathrm{kcal} / \mathrm{h} \cdot \mathrm{m}^{2}$.C. A granulometria do EPS fica em torno de $0,5 \mathrm{~cm}$, e seu formato é em sua grande maioria esférico.

\section{RESULTADOS}

\subsection{MASSA ESPECÍFICA}

Com a adição de EPS, houve uma redução da massa específica do concreto, conforme esperado, como mostra a tabela 4.

Tabela 4: Massa específica em função do EPS

\begin{tabular}{ccc}
\hline Traço & Dosagem de EPS $\left(\mathbf{m}^{\mathbf{3}}\right)$ & Massa Específica $\left(\mathbf{k g} / \mathbf{d m}^{\mathbf{3}}\right)$ \\
\hline T-0 & 0 & 2,42 \\
T-1 & 0,0091 & 2,30 \\
T-2 & 0,02 & 2,05 \\
T-3 & 0,04 & 1,84 \\
\hline
\end{tabular}

Fonte: AUTOR, 2015. 


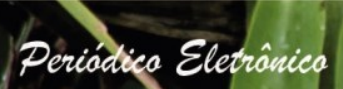

No entanto, nem todos os traços atingiram as especificações para serem considerados concretos leves, de acordo com a NS 3473 E (1992) que especifica concretos com massa específica abaixo de $2,2 \mathrm{~kg} / \mathrm{dm}^{3}$, o T-2 e o T-3 são leves; em relação a RILEM (1975) somente o T-3 é considerado leve, pois especifica massa específica menor que $2,0 \mathrm{~kg} / \mathrm{dm}^{3}$; e segundo o ACl 213R-87, somente o T-3 é leve, pois apresenta massa específica inferior à $1,85 \mathrm{~kg} / \mathrm{dm}^{3}$, conforme tabela 5 .

Tabela 5: Comparativo das massas específicas obtidas com os documentos normativos internacionais

\begin{tabular}{ccc}
\hline Referência & Massa específica $\left(\mathbf{k g} / \mathbf{d m}^{\mathbf{3}}\right)$ & Traços que se encaixam nas referências \\
\hline RILEM (1975) & $<2,00$ & $\mathrm{~T}-3$ \\
ACl 213R-87 (1997) & $1,40-1,85$ & $\mathrm{~T}-3$ \\
NS 3473 E (1992) & $1,20-2,20$ & $\mathrm{~T}-2$ e T-3 \\
\hline
\end{tabular}

Fonte: AUTOR, 2015.

Ainda que nem todos os traços atingiram os parâmetros mínimos para serem considerados leves, aconteceu o que se esperava, quanto maior o teor de EPS, menor foi a massa especifica do concreto.

\subsection{ABATIMENTO DO TRONCO DE CONE (SLUMP TEST)}

Devido à baixa massa específica dos agregados leves, no caso do abatimento de tronco de cone, os concretos leves apresentam um abatimento menor que os concretos convencionais, devido essencialmente à menor deformação do concreto leve pela gravidade (NM 67/1998), conforme tabela 6.

Tabela 6: Slump test em relação ao teor de EPS

\begin{tabular}{ccc}
\hline Traço & Dosagem de EPS (g) & Slump Test (mm) \\
\hline T-0 & 0 & 70 \\
T-1 & 100 & 60 \\
T-2 & 200 & 60 \\
T-3 & 400 & 40 \\
\hline
\end{tabular}

Fonte: AUTOR, 2015.

Observa-se que o EPS diminuiu consideravelmente o abatimento do concreto, que define sua trabalhabilidade, portanto aumentando o teor de EPS no concreto e mantendo o fator água/cimento o resultado será um concreto menos trabalhável.

A tabela 7 mostra os valores de abatimento recomendados pelo $\mathrm{ACl}$, para vários tipos de construções. 
Tabela 7: Valores de abatimento recomendados pelo $\mathrm{ACl}$.

\begin{tabular}{ccc}
\hline Tipos de Construção & \multicolumn{2}{c}{ Abatimento (mm) } \\
\cline { 2 - 3 } & Máximo* & Mínimo \\
\hline Paredes de fundações armadas e sapatas & 75 & 25 \\
Sapatas não armadas, caixões e paredes de vedação & 75 & 25 \\
Vigas e paredes armadas & 100 & 25 \\
Pilares de edifício & 100 & 25 \\
Pavimentos e lajes & 75 & 25 \\
Concreto massa & 50 & 25 \\
\hline
\end{tabular}

*Pode ser aumentada em $25 \mathrm{~mm}$ com o uso de métodos de consolidação que não a vibração Fonte: MEHTA; MONTEIRO; apud ACI.

Observando os valores de abatimento recomendados para peças estruturais, pode-se afirmar que mesmo que nenhum traço tenha atingido a abatimento do concreto original, que era de $200 \mathrm{~mm}$, todos os abatimentos obtidos estão dentro das recomendações do $\mathrm{ACl}$.

\subsection{ENSAIOS DE RESISTÊNCIA}

\subsubsection{Resistência à compressão axial}

Como já era esperado com o aumento do teor de EPS houve uma redução na resistência à compressão do concreto. Para o estudo dos dados foi feita uma análise estatística e desenvolvido um gráfico de dispersão dos dados e uma função matemática para cada idade de ensaio dos corpos de prova.

Os resultados obtidos de resistência à compressão axial com idade de 3 dias podem ser observados na tabela 8 , e a dispersão dos dados juntamente com a função matemática do tratamento conforme figura 1.

Tabela 8: Dispersão estatística da resistência à compressão axial aos 3 dias

\begin{tabular}{|c|c|c|c|c|c|c|c|c|c|}
\hline \multirow[t]{2}{*}{ Traço } & \multicolumn{2}{|c|}{$\begin{array}{c}\text { Corpos de } \\
\text { Prova (MPa) }\end{array}$} & \multirow[t]{2}{*}{$\begin{array}{l}\text { Média } \\
\text { (MPa) }\end{array}$} & \multirow{2}{*}{$\begin{array}{c}\text { Desvio } \\
\text { Padrão } \\
\text { (MPa) }\end{array}$} & \multirow[t]{2}{*}{$\begin{array}{l}\text { Coeficiente de } \\
\text { Variação (\%) }\end{array}$} & \multirow{2}{*}{$\begin{array}{c}\text { Margem } \\
\text { de Erro } \\
(\mathrm{MPa})\end{array}$} & \multicolumn{2}{|c|}{$\begin{array}{l}\text { Índice de Confiança } \\
(95 \%)\end{array}$} & \\
\hline & CP 1 & CP 2 & & & & & $\begin{array}{c}\text { Lmín } \\
\text { (MPa) }\end{array}$ & $\begin{array}{l}\text { Lmáx } \\
\text { (MPa) }\end{array}$ & \\
\hline T-0 & 40,1 & 39,6 & 39,85 & 0,4 & 0,89 & 3,2 & 36,7 & 43,0 & A \\
\hline T-1 & 35,1 & 32,7 & 33,90 & 1,7 & 5,01 & 15,2 & 18,7 & 49,1 & A \\
\hline T-2 & 15,4 & 15,7 & 15,55 & 0,2 & 1,36 & 1,9 & 13,6 & 17,5 & B \\
\hline $\mathrm{T}-3$ & 10,5 & 10,9 & 10,70 & 0,3 & 2,64 & 2,5 & 8,2 & 13,2 & C \\
\hline
\end{tabular}

Fonte: AUTOR, 2015.

Observando os dados encontrados na dispersão pode-se analisar os resultados mais estatisticamente. $O$ desvio padrão da resistência à compressão aos 3 dias foi relativamente baixo, tendo uma variação um pouco maior somente no T-1. O coeficiente de variação sem EPS (T-0) atinge $0,89 \%$, o T- 1 atinge 5,01\%, o T-2 atinge $1,36 \%$ e 0 T-3 atinge $2,64 \%$.

A margem de erro foi maior no T-1, o que resultou num intervalo muito grande entre o limite mínimo e máximo das resistências. 


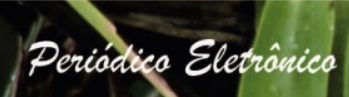

Observando os intervalos pode-se afirmar que os tratamentos T-0 e T-1 não se diferenciaram estatisticamente, ou seja, estão contidos em um mesmo intervalo, e já os tratamentos T-2 e T3 se diferenciaram de todos os outros, essa análise é representada pelas letras na lateral direita da tabela 8 , os tratamentos que tem a mesma letra não se diferenciam, e os que possuem letras diferentes se diferenciam estatisticamente.

Figura 1: Dispersão polinomial dos dados de resistência à compressão axial aos 3 dias

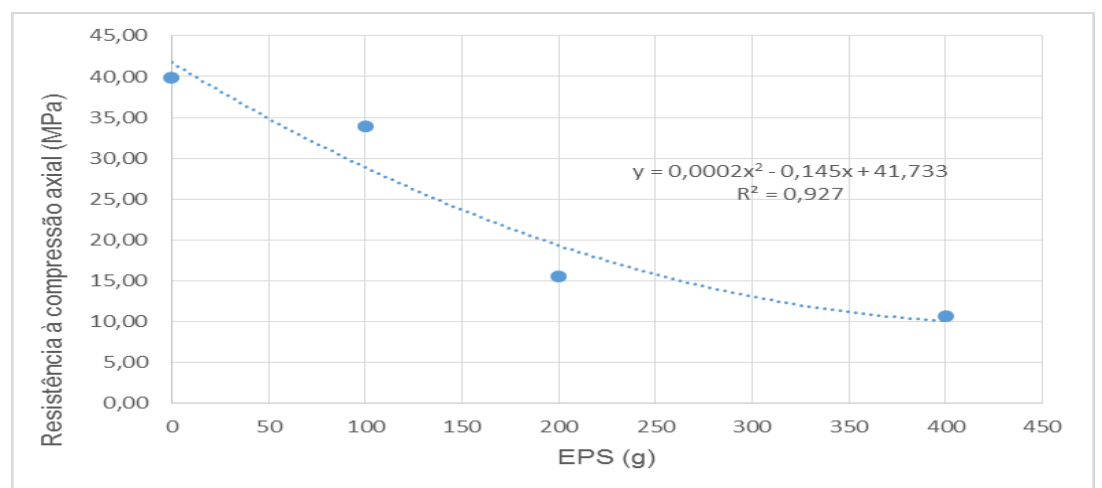

Fonte: AUTOR, 2015.

Do ponto de vista estritamente estatístico, considerando somente o intervalo de 0 a $400 \mathrm{~g}$ de EPS a regressão que mais se adequou a dispersão dos dados foi a polinomial, pois os pontos se aproximavam mais de uma curva. $E$ a função matemática que expressa essa regressão é dada por: $y=0,0002 x^{2}-0,145 x+41,733$

Neste caso o $R^{2}$ (coeficiente de explicação) encontrado foi de 0,927, ou seja, 92,7\% das variações de y são explicadas pelas variações de $x$ através da função encontrada.

Do ponto de vista estatístico, a dispersão polinomial se ajusta melhor aos pontos, mas do ponto de vista técnico e real, a dispersão linear seria mais adequada. Observando a dispersão polinomial nota-se que se a curva tende a ser uma assíntota, ou seja, ela estabiliza; e na realidade se dobrar a quantidade de EPS a resistência tende a cair mais como mostra a figura 2 , e não a se manter.

Figura 2: Dispersão linear dos dados de resistência à compressão axial aos 3 dias

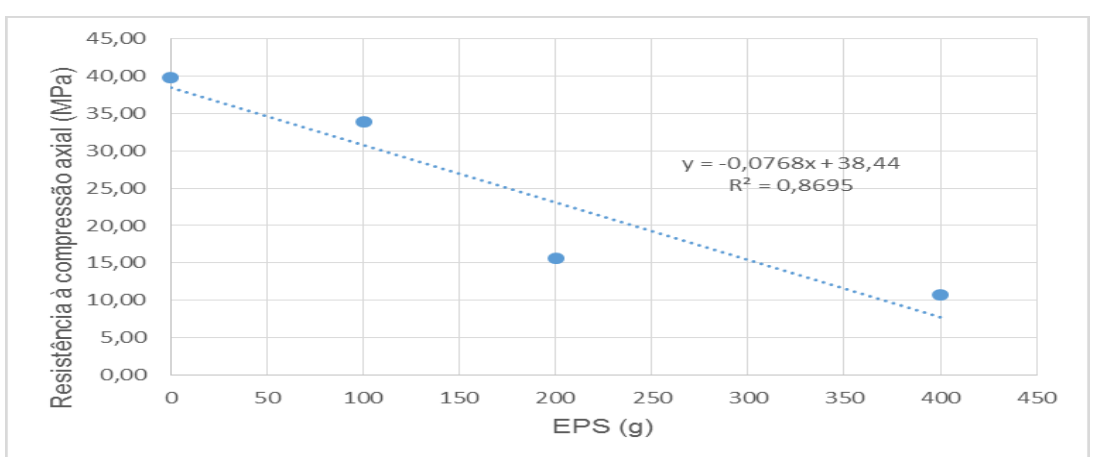

Fonte: AUTOR, 2015. 
Na dispersão linear a função matemática que expressa a regressão é dada por: $y=-0,0768 x+$ 38,44 e o coeficiente de explicação $\left(R^{2}\right)$ neste caso cai para 0,8695 .

Os resultados obtidos de resistência à compressão axial com idade de 7 dias podem ser observados na tabela 9, e a dispersão dos dados juntamente com a função matemática do tratamento conforme figura 3.

Tabela 9: Dispersão estatística da resistência à compressão axial aos 7 dias

\begin{tabular}{|c|c|c|c|c|c|c|c|c|c|}
\hline \multirow[t]{2}{*}{$\begin{array}{l}\text { EPS } \\
\text { (g) }\end{array}$} & \multicolumn{2}{|c|}{$\begin{array}{l}\text { Corpos de } \\
\text { Prova (MPa) }\end{array}$} & \multirow[t]{2}{*}{$\begin{array}{l}\text { Média } \\
\text { (MPa) }\end{array}$} & \multirow{2}{*}{$\begin{array}{l}\text { Desvio } \\
\text { Padrão } \\
\text { (MPa) }\end{array}$} & \multirow[t]{2}{*}{$\begin{array}{c}\text { Coeficiente de } \\
\text { Variação (\%) }\end{array}$} & \multirow{2}{*}{$\begin{array}{c}\text { Margem } \\
\text { de Erro } \\
(\mathrm{MPa})\end{array}$} & \multicolumn{2}{|c|}{$\begin{array}{c}\text { Índice de Confiança } \\
(95 \%)\end{array}$} & \\
\hline & CP 1 & CP 2 & & & & & $\begin{array}{l}\text { Lmín } \\
\text { (MPa) }\end{array}$ & $\begin{array}{l}\text { Lmáx } \\
\text { (MPa) }\end{array}$ & \\
\hline $\mathrm{T}-0$ & 45,9 & 49,6 & 47,75 & 2,6 & 5,48 & 23,5 & 24,2 & 71,3 & A \\
\hline T-1 & 36,2 & 37,4 & 36,80 & 0,8 & 2,31 & 7,6 & 29,2 & 44,4 & A \\
\hline T-2 & 17,6 & 15,1 & 16,35 & 1,8 & 10,81 & 15,9 & 0,5 & 32,2 & A \\
\hline T-3 & 11,9 & 12,5 & 12,20 & 0,4 & 3,48 & 3,8 & 8,4 & 16,0 & A \\
\hline
\end{tabular}

Fonte: AUTOR.

De acordo com os dados encontrados na tabela 18, o desvio padrão foi baixo e uniforme em relação aos quatro tratamentos. Já o coeficiente de variação aumentou em relação ao de 3 dias. A margem de erro foi significativa principalmente no tratamento T-0 e T-2, resultando em grandes intervalos entre o limite mínimo e máximo. Os tratamentos não possuem diferença estatística entre eles, pois todos os intervalos se sobrepõem.

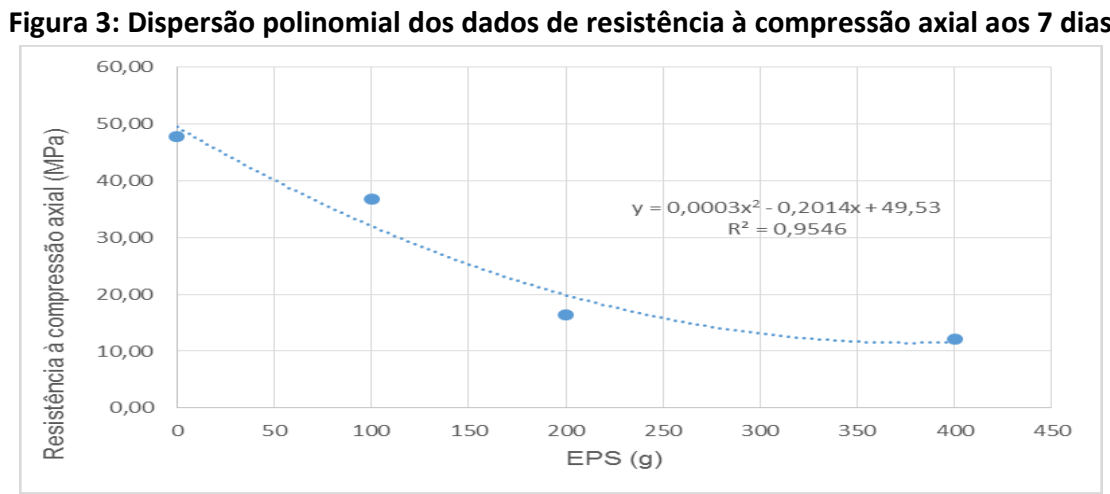

Fonte: AUTOR, 2015.

Para o intervalo de 0 a 400g de EPS a regressão mais adequada para a dispersão dos dados de sete dias também foi a polinomial, e a função matemática que representa essa curva é dada por: $y=0,0003 x^{2}-0,2014 x+49,53$. O coeficiente de explicação encontrado foi de 0,9546 . Assim como nos resultados aos 3 dias, aos 7 dias estatisticamente a regressão polinomial se ajusta melhor aos pontos, mas tecnicamente a regressão linear explica melhor o que acontece quando se adiciona EPS no concreto, conforme a figura 4. 
Figura 4: Dispersão linear dos dados de resistência à compressão axial aos 7 dias.

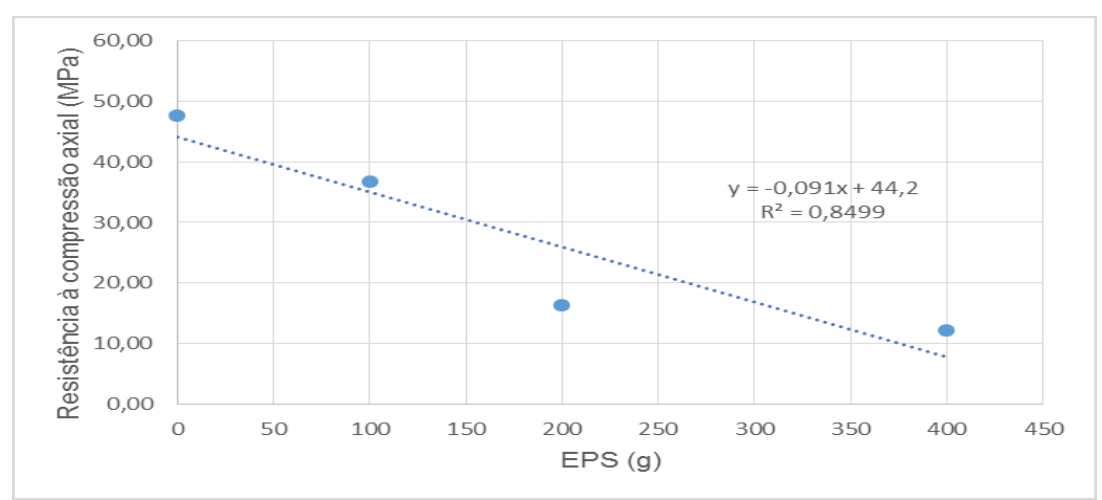

Fonte: AUTOR, 2015.

A função que representa a regressão linear dos dados é dada por: $y=-0,091 x+44,2$. 0 coeficiente de explicação que representa estes dados também é menor em relação a regressão polinomial, sendo 0,8499 .

Os resultados obtidos de resistência à compressão axial com idade de 14 dias podem ser observados na tabela 10, e a dispersão dos dados juntamente com a função matemática e o coeficiente de explicação do tratamento conforme figura 5.

Tabela 10: Dispersão estatística da resistência à compressão axial aos 14 dias.

\begin{tabular}{|c|c|c|c|c|c|c|c|c|c|}
\hline \multirow[t]{2}{*}{$\begin{array}{l}\text { EPS } \\
\text { (g) }\end{array}$} & \multicolumn{2}{|c|}{$\begin{array}{c}\text { Corpos de } \\
\text { Prova (MPa) }\end{array}$} & \multirow[t]{2}{*}{$\begin{array}{l}\text { Média } \\
\text { (MPa) }\end{array}$} & \multirow{2}{*}{$\begin{array}{l}\text { Desvio } \\
\text { Padrão } \\
\text { (MPa) }\end{array}$} & \multirow[t]{2}{*}{$\begin{array}{l}\text { Coeficiente de } \\
\text { Variação (\%) }\end{array}$} & \multirow{2}{*}{$\begin{array}{c}\text { Margem } \\
\text { de Erro } \\
\text { (MPa) }\end{array}$} & \multicolumn{2}{|c|}{$\begin{array}{l}\text { Índice de Confiança } \\
\qquad(95 \%)\end{array}$} & \\
\hline & CP 1 & CP 2 & & & & & $\begin{array}{l}\text { Lmín } \\
\text { (MPa) }\end{array}$ & $\begin{array}{l}\text { Lmáx } \\
\text { (MPa) }\end{array}$ & \\
\hline T-0 & 54,3 & 55,8 & 55,05 & 1,1 & 1,93 & 9,5 & 45,5 & 64,6 & $\bar{A}$ \\
\hline T-1 & 46,5 & 45,4 & 45,95 & 0,8 & 1,69 & 7,0 & 39,0 & 52,9 & A \\
\hline $\mathrm{T}-2$ & 18,6 & 17,8 & 18,20 & 0,6 & 3,11 & 5,1 & 13,1 & 23,3 & B \\
\hline$T-3$ & 12,6 & 12,9 & 12,75 & 0,2 & 1,66 & 1,9 & 10,8 & 14,7 & B \\
\hline
\end{tabular}

Fonte: AUTOR, 2015.

Conforme dados da tabela 19, o desvio padrão apresentou-se baixo e uniforme. O coeficiente de variação também foi considerado baixo. A margem de erro foi mediana, variando de 1,9 à 9,5MPa. Observando os intervalos entre os limites mínimos e máximos dos tratamentos, podese afirmar que os tratamentos T-0 e T-1 não se diferem estatisticamente, mas se diferem dos tratamentos T-2 e T-3, mas estes também não se diferenciam entre si. 
Figura 5: Dispersão polinomial dos dados de resistência à compressão axial aos 14 dias.

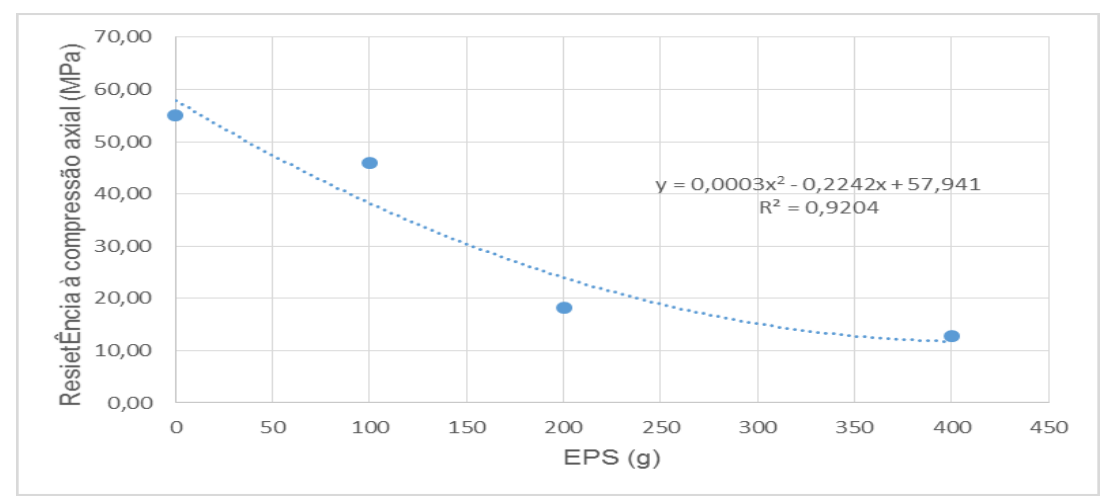

Fonte: AUTOR, 2015.

Considerando o intervalo de EPS de 0 à 400g, a regressão mais adequada continua sendo a polinomial, e a função matemática que representa melhor os dados é dada por: $y=0,0003 x^{2}$ $0,2242 x+57,941$ e o coeficiente de explicação encontrado para a regressão foi de 0,9204. Novamente a regressão polinomial se adequa melhor aos pontos, mas na realidade a regressão linear possui uma veracidade maior tecnicamente, aumentando a quantidade de EPS a resistência à compressão tende a diminuir, conforme figura 6 .

Figura 6: Dispersão linear dos dados de resistência à compressão axial aos 14 dias.

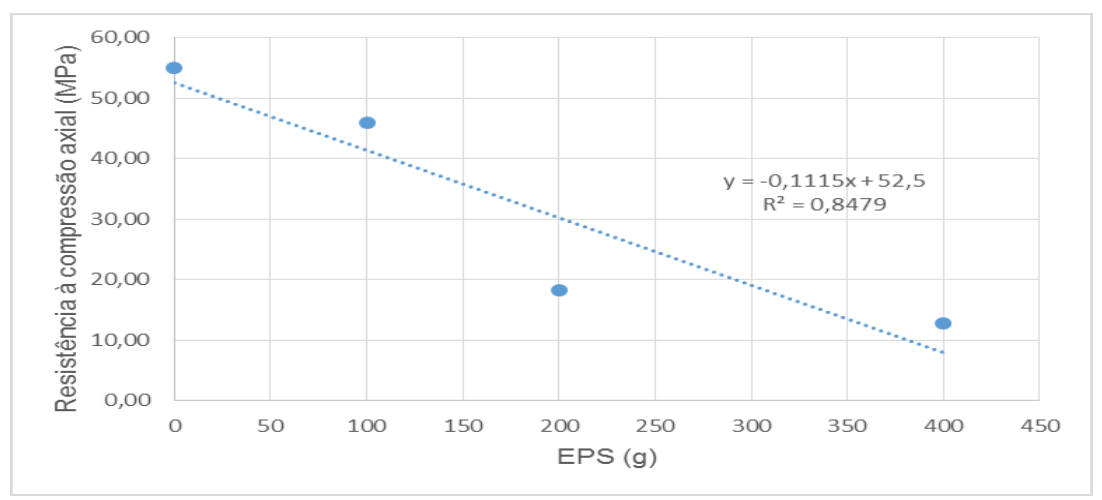

Fonte: AUTOR, 2015.

A função que representa a regressão linear dos dados obtidos aos 14 dias é dada por: $y=-$ $0,1115 x+52,5$. E o coeficiente de explicação é novamente menor que o da regressão polinomial, é de 0,8479 .

Os resultados obtidos de resistência à compressão axial com idade de 28 dias podem ser observados na tabela 11, e a dispersão dos dados juntamente com a função matemática e o coeficiente de explicação do tratamento conforme figura 7. 
Tabela 11: Dispersão estatística da resistência à compressão axial aos 28 dias.

\begin{tabular}{|c|c|c|c|c|c|c|c|c|c|}
\hline \multirow[t]{2}{*}{$\begin{array}{l}\text { EPS } \\
\text { (g) }\end{array}$} & \multicolumn{2}{|c|}{$\begin{array}{c}\text { Corpos de } \\
\text { Prova (MPa) }\end{array}$} & \multirow[t]{2}{*}{$\begin{array}{l}\text { Média } \\
\text { (MPa) }\end{array}$} & \multirow{2}{*}{$\begin{array}{c}\text { Desvio } \\
\text { Padrão } \\
\text { (MPa) }\end{array}$} & \multirow[t]{2}{*}{$\begin{array}{c}\text { Coeficiente de } \\
\text { Variação (\%) }\end{array}$} & \multirow{2}{*}{$\begin{array}{c}\text { Margem } \\
\text { de Erro } \\
(\mathrm{MPa})\end{array}$} & \multicolumn{2}{|c|}{$\begin{array}{l}\text { Índice de Confiança } \\
\text { (95\%) }\end{array}$} & \\
\hline & CP 1 & CP 2 & & & & & $\begin{array}{l}\text { Lmín } \\
\text { (MPa) }\end{array}$ & $\begin{array}{l}\text { Lmáx } \\
\text { (MPa) }\end{array}$ & \\
\hline T-0 & 59,6 & 63,2 & 61,40 & 2,5 & 4,15 & 22,9 & 38,5 & 84,3 & A \\
\hline $\mathrm{T}-1$ & 47,3 & 45,1 & 46,20 & 1,6 & 3,37 & 14,0 & 32,2 & 60,2 & A \\
\hline T-2 & 21,3 & 20,7 & 21,00 & 0,4 & 2,02 & 3,8 & 17,2 & 24,8 & B \\
\hline T-3 & 11,7 & 12,9 & 12,30 & 0,8 & 6,90 & 7,6 & 4,7 & 19,9 & B \\
\hline
\end{tabular}

Fonte: AUTOR, 2015.

Conforme os dados apresentados na tabela 16, o desvio padrão apresentou-se baixo e uniforme. Já o coeficiente de variação não foi considerado baixo: no T-0 os desvios em relação à média atinge $4,15 \%$, no T-1 atinge $3,37 \%$, no T-2 atinge $2,02 \%$ e no T-3 atinge $6,90 \%$.

A margem de erro foi alta, variando de 3,8 à 22,9MPa. Observando os intervalos entre os limites mínimos e máximos dos tratamentos, pode-se afirmar que os tratamentos T-0 e T-1 não se diferem estatisticamente, mas se diferem dos tratamentos T-2 e T-3, mas estes também não se diferenciam entre si.

Figura 7: Dispersão polinomial dos dados de resistência à compressão axial aos 28 dias.

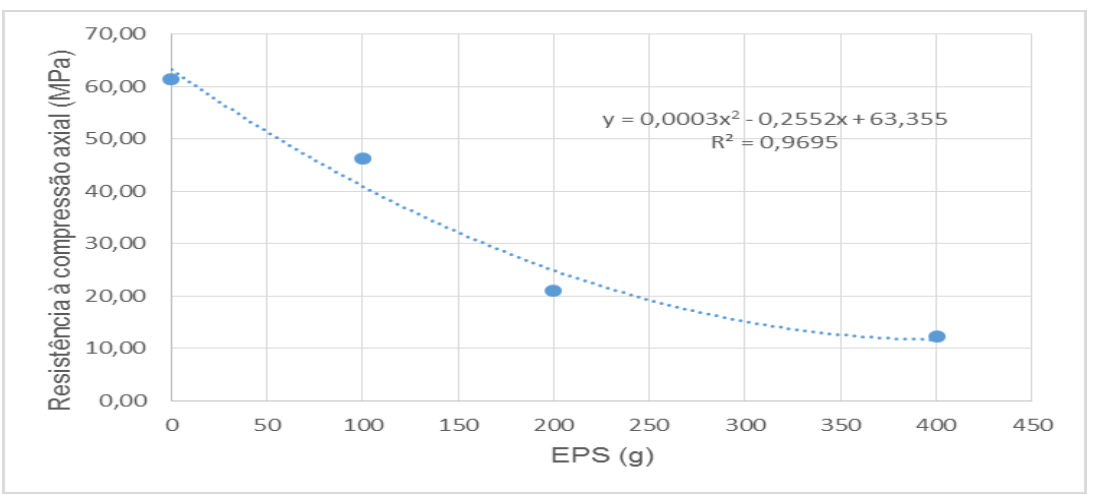

Fonte: AUTOR, 2015.

Considerando o intervalo de EPS de 0 à 400g, a regressão mais adequada continua sendo a polinomial, e a função matemática que representa melhor os dados é dada por: $y=0,0003 x^{2}$ $0,2552 x+63,355$ e o coeficiente de explicação encontrado para a regressão foi de 0,9695 . Novamente a regressão polinomial se adequa melhor aos pontos, se tratando de estatística, mas na realidade a regressão linear possui uma veracidade maior tecnicamente, aumentando a quantidade de EPS a resistência à compressão tende a diminuir, conforme figura 8. 
Figura 8: Dispersão linear dos dados de resistência à compressão axial aos 28 dias.

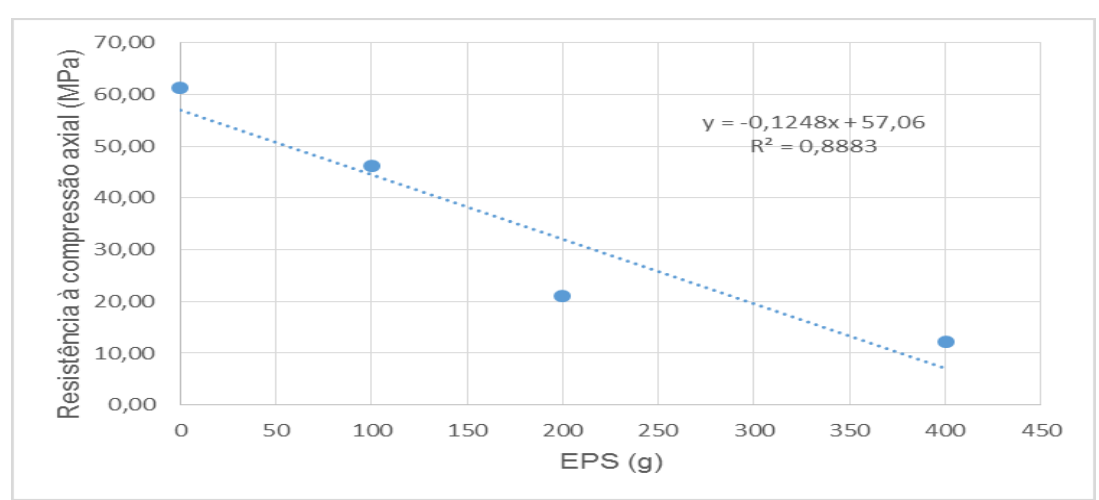

Fonte: AUTOR, 2015.

A função que representa a regressão linear dos dados obtidos aos 28 dias é dada por: $y=-$ $0,1248 x+57,06$ e o coeficiente de explicação é novamente menor que o da regressão polinomial, é de 0,8883 .

Os resultados das idades avaliadas corroboram as tendências estatísticas e experimentais apresentadas, o que indica que a moldagem e ensaio dos corpos de prova seguiram um padrão de qualidade.

Ainda em relação a resistência à compressão a axial, o T-3 foi o único concreto que não pôde ser considerado estrutural, pois apresentou resistência à compressão aos 28 dias de apenas 12,3MPa, sendo inferior ao mínimo que é de 17,2MPa.

\subsubsection{Resistência à tração por compressão diametral}

Assim como a resistência à compressão axial, a resistência à tração por compressão diametral também tende a diminuir com a adição de agregados leves. Os resultados obtidos por este ensaio estão dispostos na tabela 12.

Tabela 12: Resistência à tração por compressão diametral em função do EPS.

\begin{tabular}{ccc}
\hline Traço & Dosagem de EPS (g) & Resistência à Tração por Compressão Diametral (MPa) \\
\hline T-0 & 0 & 6,71 \\
T-1 & 100 & 4,81 \\
T-2 & 200 & 2,17 \\
T-3 & 400 & 1,37 \\
\hline
\end{tabular}

Fonte: AUTOR, 2015.

\subsection{FATOR DE EFICIÊNCIA}

O fator de eficiência do concreto (FE) consiste na razão entre a resistência à compressão e a massa específica aparente. Não existe um parâmetro para o concreto leve estrutural, somente para o concreto leve de alto desempenho que de acordo com SPITZNER (1994) e ARMELIN et 


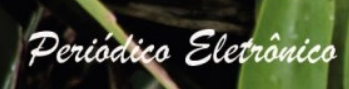

al. (1994) deve ser superior à $25 \mathrm{MPa} \cdot \mathrm{dm}^{3} / \mathrm{kg}$. Os valores de FE podem ser observados na tabela 13.

Tabela 13: Fator de Eficiência

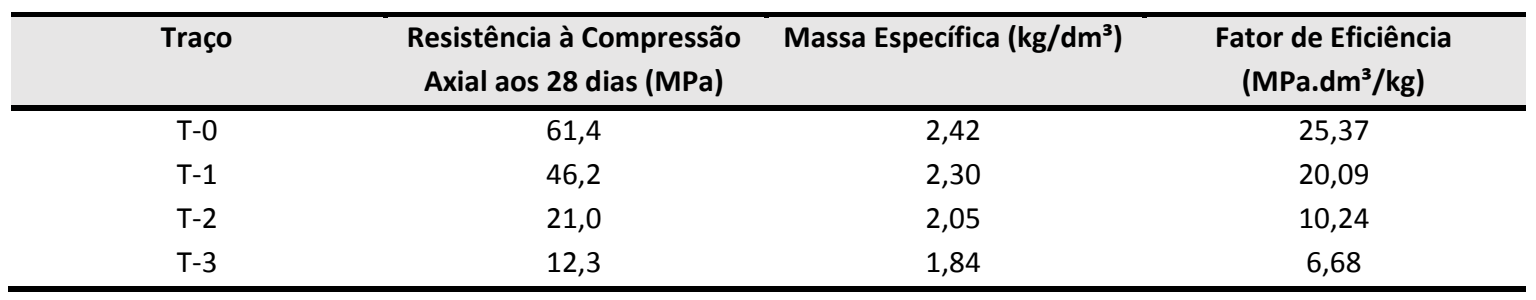

Fonte: AUTOR, 2015.

Analisando os dados apresentados apenas o T-0, que não possui adição de EPS, que apresentou um fator de eficiência maior que $25 \mathrm{MPa} \cdot \mathrm{dm}^{3} / \mathrm{kg}$.

\subsection{ABSORÇÃO DE ÁGUA}

Com o aumento do teor de EPS no concreto a absorção de água também aumentou, isso se deve ao grande índice de vazios do EPS, que em sua composição $98 \%$ é ar. O T-0, sem adição de EPS, apresentou uma absorção de água de 0,48\%; o T-1, com adição de $100 \mathrm{~g}$ de EPS, absorveu $0,62 \%$; o T-2, com adição de $200 \mathrm{~g}$ de EPS, teve uma absorção de $0,70 \%$ e o T-3, com adição de $400 \mathrm{~g}$, absorveu $1,14 \%$.

\section{CONCLUSÕES}

A massa específica de todos os traços estudados tiveram um redução com a adição do EPS, sendo que somente o T-2 e o T-3, com 200 e 400g de EPS, são leves de acordo com as três normas estudadas. Quanto ao abatimento de tronco de cone, nenhum dos traços estudados atingiram o abatimento de $200 \mathrm{~mm}$ do concreto original, mas todos ficaram dentro do intervalo recomendado pelo $\mathrm{ACl}$. Um fator que causou essa diminuição no abatimento do concreto foi o próprio EPS, pois ele possui baixa massa específica, o que consequentemente diminui a massa específica do concreto, e sendo o concreto mais leve, este sofre menor deformação pela gravidade.

Levando em consideração as normas observadas e os resultados obtidos somente o T-2 (200g de EPS) pode ser considerado concreto leve estrutural, pois apresentou resistência à compressão axial superior a mínima exigida e massa específica inferior a $2,20 \mathrm{~kg} / \mathrm{dm}^{3}$, de acordo com a NS 3473 E. O T-3 (400g de EPS) apresentou massa específica menor que o estabelecido pelas três normas consideradas, porém não atingiu a resistência à compressão mínima de 17,2 MPa, exigida pelo $A C l$ 213R-87 para ser considerado concreto estrutural leve. Com a adição do EPS, a absorção de água do concreto também aumentou, tendo o T-1 um aumento de $30 \%$, o T-2 um aumento de $46 \%$ e o T-3 um aumento de $137 \%$. Possivelmente, 


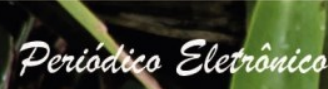

esse grande aumento da absorção de água foi devido a fase de transição do agregado com a pasta de cimento, pois o agregado de rocha possui uma composição química próxima da composição química do cimento; já o EPS não se assemelha nem um pouco com a composição dos outros materiais do concreto, sendo ele um plástico. Com isso não há aderência do EPS com a pasta de cimento, ficando um vazio ao redor do EPS, o que facilita a absorção e permeabilidade de água no concreto.

\section{REFERÊNCIAS BIBLIOGRÁFICAS}

ABNT. ASSOCIAÇÃO BRASILEIRA DE NORMAS TÉCNICAS. NBR 9778: Argamassa e concreto endurecidos Determinação da absorção de água, índice de vazios e massa específica Rio de Janeiro: ABNT, 2009.

ABNT. ASSOCIAÇÃO BRASILEIRA DE NORMAS TÉCNICAS. NBR 5739: Concreto - Ensaio de compressão de corpos de prova cilíndricos. Rio de Janeiro, 1994.

ABNT. ASSOCIAÇÃO BRASILEIRA DE NORMAS TÉCNICAS. NM 35 - Agregados Leves para Concreto Estrutural Especificações. Rio de Janeiro, 1995.

ABNT. ASSOCIAÇÃO BRASILEIRA DE NORMAS TÉCNICAS. NM 67 - Concreto - Determinação da consistência pelo abatimento do tronco de cone. Rio de Janeiro, 1998.

AMERICAN CONCRETE INSTITUTE (ACI). Advances in concrete technology - proceeding second canmet/ aci international symposium. ACI SP 154-95. Las Vegas, Nevada, USA, 1995.

AMERICAN CONCRETE INSTITUTE (ACI). Guide for Structural Lightweight Aggregate Concrete. ACI 213R-87. ACI Manual of Concrete Pratice, Part 1, 27p., 1997.

AMERICAN SOCIETY FOR TESTING AND MATERIALS (ASTM). Standard Specification for Portland Cement. ASTM C150. West Conshohocken, PA, 2012.

CATOIA, T. Concreto Ultraleve estrutural com pérolas de EPS: Caracterização do material e estudo de sua aplicação em lajes. Tese de doutorado em Engenharia de Estruturas, Escola de Engenharia de São Carlos, Universidade de São Paulo, São Carlos, São Paulo, 2012.

DEUTSCHES INSTITUT F. Plastics - Symbols and abbreviated terms DIN ISO 1043-1. Basic polymers and their special characteristics. 2001.

FONSECA, J.S., et al. Estatística Aplicada, Editora Atlas, 2a Edição. São Paulo, 1985.

HOLM, T.A. Specified density concrete - A transition. In: Internacional Symposium on Structural Lightweight Agregate Concrete, 2. Kristiansand, Norway, 2000. Proceedings, p.37-46.

LANGLEY, W.S. et al. ACI Special Publication, n. 154, pp. 543-564, 1995.

MEHTA, Kumar P., MONTEIRO, PAULO J.M. Concreto: Estrutura, Propriedades e Materiais. Editora Pini, 1a Edição. São Paulo, 1994.

ROSSIGNOLO, J. A. Concreto leve estrutural: produção, propriedades, microestrutura e aplicações. Editora Pini, 1ạ Edição. São Paulo, 2009.

SILMIX. Ficha Técnica da Sílica Ativa Silmix. Canoas, RS.

SILVA, D. O. B., et al. Dosagem de EPS no Concreto Leve de Alta Resistência. São Paulo: IBRACON, 2014. 


\section{Periádica Eletranica

SPITZNER, J. High-Strength LWA Concrete. High-Strength Concrete. RILEM Cap.II - Aggregates. 1994. 